\title{
Well-being in the Workplace: the Case of Working Pensioners
}

\author{
Mikhail Kaz $^{\mathrm{a}, \mathrm{b} *}$, Anastasiya Kuchkartaeva ${ }^{\mathrm{b}}$ \\ * Corresponding author: Michail Kaz, misk3@mail.ru \\ ${ }^{a}$ Tomsk State University, pr. Lenina 36, Tomsk, 634050, Russia \\ ${ }^{b}$ Tomsk Polytechnic University, pr. Lenina 30, Tomsk, 634050, Russia
}

\begin{abstract}
http://dx.doi.org/10.15405/epsbs.2017.01.41

The factors that affect the well-being of working pensioners are investigated in the article. We have not used as a data source the traditional methods of obtaining information from respondents (survey results or interviews). However, we have used the data presented in the social networks. The type of analyzed data is qualitative, it limited us in the choice of methods of analysis. On the other hand, the using of non-classical source of social information stimulated us to search the ways in order to improve the technology of working with such a data array as an important independent research problem. An adequate method must identify a system of subjective perceptions of a particular individual, but not to impose it from the outside. This encouraged us to use the tools of content analysis' methods and multidimensional scaling data in the research process. The results of multidimensional scaling allowed us to find the major groups of the problems dominant in the minds of working pensioners. In addition, it was proposed the approach in the article, that could solve the problem of retrieving and analyzing the information that is circulating in the social networks, it also allowed us to expand the opportunities for triangulation of data (the using various types of information sources during the research of one phenomena). This approach will enhance the objectivity of scientific results.
\end{abstract}

(C) 2017 Published by Future Academy www.FutureAcademy.org.uk

Keywords: Well-being; cognitive-value approach; quality of elderly people's life.

\section{Introduction}

The reduction of the population by 11 million people and the working-age population by 13 million is "the most optimistic" forecast of Russian population until 2030 (Vishnevskij, 2010). This is largely explained by the existed structure in the last century of the age composition of Russian population, due to known historical events of the first half of the 20th century and fertility decline of 90 years (see the restriction columns at the bottom of the pyramid in Figure 1). All these facts will lead to a sharp decline in the population of working age in 2019 and especially in 2029 (see Figure 1. dashed and solid 
line, respectively). This will cause a reduction in supply in the labor market from the younger age groups. It will require active involvement people of retirement age in the labor activity.

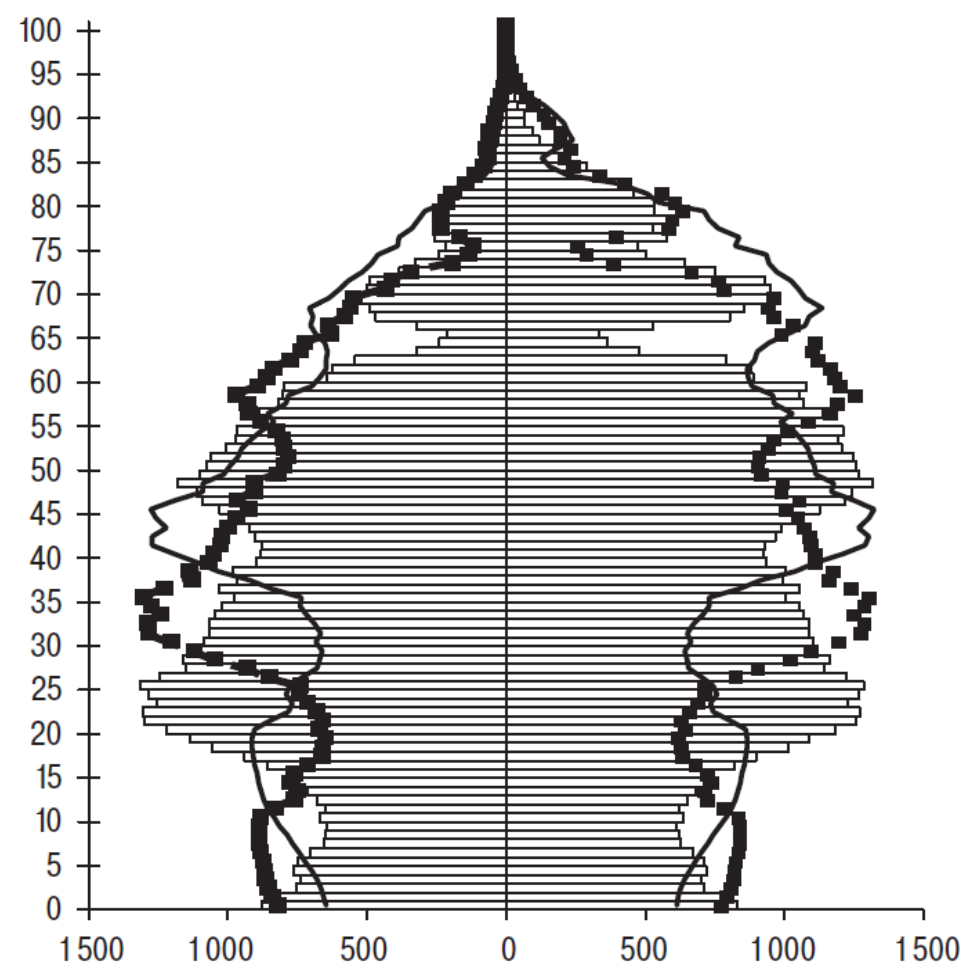

Fig.1. The age pyramid of Russian population at the beginning of 2009 (bars); according to the medium variant of Rosstat forecast at the beginning of 2019 (dotted line); according to the medium variant of Rosstat forecast at the beginning of 2029 (solid line), thous. People (Vishnevskij, 2010)

Thus, the need for greater attention to the problems of working pensioners is obvious. However, the analysis shows that if the study of well-being of working-age employees is the subject of numerous investigations, the work relating to the welfare of pensioners is much fewer. As for the researches on the problems of well-being and the quality of working life of working pensioners, these works are extremely rare. We hope that our research will contribute to the reduction number of gaps in this field of knowledge.

\section{Research problem area}

How to get into the world of working pensioner?

One way is to use the qualitative research methods. They are based on the idea of the uniqueness and diversity of each fact of the social life, and therefore these methods treat with caution to the generalizations of the data. The interpretation of the collected data array in the process of qualitative research involves several steps (Charmaz, 2006):

- the original coding is a brief formulation of topics contained in each line of text;

- the focused coding is an association of topics identified in the previous step into a larger category;

- the theoretical coding is to build a model of the studied social phenomenon.

Thus, the advantage of the qualitative research is that it requires to "follow behind the text". It helps to take into account all the features of the text. However, qualitative methods have some disadvantages: 
http://dx.doi.org/10.15405/epsbs.2017.01.41

eISSN: 2357-1330 / Corresponding Author: Michail Kaz

Selection and peer-review under responsibility of the Organizing Committee of the conference

- during the process of qualitative research "one person learns another subject, but these partial individual subjective reality may not overlap" (Druzhinin, 2006);

- the qualitative research methods "only recorded the presence or absence of something, in contrast to the quantitative monitoring, which measures the degree of presence of something" (Kirk, \& Miller, 1986).

Obviously, only the use of qualitative methods in combination with quantitative methods can improve the reliability of research results. Many authors recommend to use this strategy (Neuman, 2011). It is determined our approach, implemented in the framework of the project, which may be specific as a qualitatively-quantitative approach.

As it has been shown by S. Borgatti (Table 1), the type of studied data (qualitative or quantitative) and the preferred type of analysis determine, in aggregate, the list of acceptable methods of investigation (Borgatti, 1977).

Table 1. The types of analysis, the types of study data and their relations with the research methods

\begin{tabular}{|c|c|c|c|}
\hline & & \multicolumn{2}{|c|}{ The preferred type of analysis } \\
\hline & & Qualitative & Quantitative \\
\hline \multirow{6}{*}{ 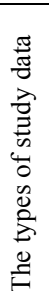 } & \multirow{4}{*}{ Qualitative } & Methods of literary criticism & \\
\hline & & & Statistical analysis of text information \\
\hline & & & Statictical anolycis of coling information \\
\hline & & Methods of thematic classification data & \\
\hline & \multirow[b]{2}{*}{ Quantitative } & \multirow[b]{2}{*}{ Methods of interpretation of statistical results } & Statistical methods \\
\hline & & & Methods of mathematical modeling \\
\hline
\end{tabular}

We have not used as a data source the traditional methods of obtaining information from respondents (survey results or interviews). However, we have used the data presented in the social networks. Because the type of investigated data was qualitative, it limited us in the choice of the methods of analysis (Table 1). On the other hand, the use of non-classical source of social information stimulated the search of ways to improve the technology of work with such a data array as an important independent research task. The achievement of positive results in the task of extracting and analyzing the information, circulating on social networks, will increase the capacity for data triangulation (appliance during the study of one phenomenon different types of information sources). It will undoubtedly increase the objectivity of scientific results.

We conducted the research of well-being of working pensioners based on the information contained on the website "Forum of Young Pensioners".

What are mostly worried this group? This is evidenced the number of users' messages in different sections of the forum, adjusted for different time length of the discussion of certain topics (calculated as the number of messages in the section / length of the presence of the topic on the forum in months). Table 2 presents the results of the evaluation of the popularity of one of the section from 53 sections of the forum. This section contains 16 topics (there are represented 1954 topics entire on the forum in all sections). 
Table 2. The average number of messages on the different topics from the website "Young Retirees" (section "Pensioners")

\begin{tabular}{|c|c|c|c|}
\hline Subject & $\begin{array}{l}\text { Total } \\
\text { messages }\end{array}$ & $\begin{array}{l}\text { The exposition of the topic } \\
\text { (months) }\end{array}$ & $\begin{array}{l}\text { The average number of messages per } \\
\text { month }\end{array}$ \\
\hline My years - my wealth & 278 & 39 & 7,128205 \\
\hline Attitude to retirement age & 991 & 95 & 10,43158 \\
\hline Working pensioners & 1018 & 36 & 28,27778 \\
\hline $\begin{array}{l}\text { Pensioner is still not a } \\
\text { sentence }\end{array}$ & 829 & 61 & 13,59016 \\
\hline $\begin{array}{l}\text { I'm preparing for } \\
\text { retirement }\end{array}$ & 930 & 29 & 32,06897 \\
\hline $\begin{array}{l}\text { Computer courses for } \\
\text { pensioners }\end{array}$ & 117 & 51 & 2,294118 \\
\hline Pensioners in the State & 151 & 39 & 3,871795 \\
\hline $\begin{array}{l}\text { The retirement age in the } \\
\text { world }\end{array}$ & 7 & 39 & 0,179487 \\
\hline $\begin{array}{l}\text { Additional earnings on } \\
\text { pension }\end{array}$ & 417 & 46 & 9,065217 \\
\hline Learning English & 57 & 34 & 1,676471 \\
\hline World News & 27 & 39 & 0,692308 \\
\hline $\begin{array}{l}\text { The title "Veteran of } \\
\text { Labour" }\end{array}$ & 79 & 63 & 1,253968 \\
\hline Learning French & 19 & 34 & 0,558824 \\
\hline $\begin{array}{l}\text { News of pension } \\
\text { legislation }\end{array}$ & 14 & 38 & 0,368421 \\
\hline Retired against officials & 105 & 50 & 2,1 \\
\hline
\end{tabular}

According to the results of the analysis, the greatest interest among registered participants cause such topics as "Working pensioners" and "I'm preparing for retirement" (Table 2).

Our further analysis was conducted on the material of the section "Working pensioners", containing at the time of the study 1018 messages and leading in the number of views (62468 views, it is $16 \%$ of the total number of views among 16 topics in this section).

During the research, we supposed that the above information, of course, gave us an idea of "the world of pensioner". However, this representation was very rough and rather surface. Moreover, it cannot satisfy the research interest if it is more complex task, such as the analysis of the issues of wellbeing pensioners.

The required method must obviously be descriptive, focused on the description of the individual employee as a special unique integrity. According to the cognitive-value approach (Kaz, \& Kuchkartaeva, 2016; Kaz, 2005, 2011), each person is a researcher, who does not simply react to stimuli, but also puts forward reasonable hypotheses, tests them in practice, constructs its own system of representations about the working environment. An adequate method must let the researcher "look at the world through the eyes of another". It means to identify the specific system of subjective perceptions of the individual, and not to impose it from the outside. H.S. Merton confirmed: "The concept of "the quality of working life" is trying to combine work and problems that have been in the interests' sphere of philosophy, theology, social sciences very long. This term integrates all the aspects of the work ethic and working conditions" (Merton, 1977).

These reasons prompted us to use the methods of content analysis and multidimensional scaling data in the process of research. 
As it was shown by K. Krippendorfom (Krippendorff, 2013), the research methods can be systematized by three parameters:

- $\quad$ unobtrusiveness is the ability of the method does not have an opposite effect on the behavior of the respondent;

- $\quad$ unstructured is the ability of the method to "work" with quality problems;

- $\quad$ sensitivity to the context is a change of the content of two identical units, depending on the context.

The analyzed information (the messages from forum) was "unobtrusiveness", "unstructured", "sensitivity to the context". According to the model of classification research techniques, proposed by K. Krippendorfom (Krippendorff, 2013), the method of "context analysis" is the most appropriate method for studying such arrays of social information. Therefore, it has been used as a method for studying the messages, posted on the social network "Young Pensioners".

The process of content analysis consists of:

- an allocation of the fragments that are relevant to the research issues (parameters that affect well-being of working pensioners) in the forum visitors' messages;

- $\quad$ assignment to each fragment, according to its semantic content, the numeric code;

- a reflection of the collected and processed information in special code cards.

In the process of content analysis it has been allocated 15 stable categories, used by the authors to describe via the messages different aspects of life, disturbing or encouraging them. Analysis of the cooccurrence frequency of these categories within each message, posted registered forum members, allowed us to quantify and present in the form of a matrix the portrait of the main aspects of working life, dominating in the minds of working pensioners and their relations.

Then, the formed matrix was transformed into a distance matrix and it was processed by multidimensional scaling via ALSCAL program implemented in the SPSS package. The minimum allowable stress improving function, after which the iterative calculation stopped, was 0.001 .

The method of multidimensional scaling, according to the definition given in the introduction of M. Davison work, is a "mathematical tools for processing of the data pair similarities, connections or relations between the analyzed objects to present these objects in the form of points of some coordinate space" (Ajvazjan, \& Kamenskij, 1988). The coordinate axes of the space are the latent signs by which the respondent evaluates and classifies the objects.

The results of the analysis with the use of the third-dimensional scaling are shown in Figure 2. The function of stress, reflecting the difference between the results of model calculations of distances between the studied categories and the distances in the original data array, is 0.203 . This indicates good correspondence the obtained result with original data (stress function can take values ranging from 0 to 1. Value zero means no difference between the results of modeling and the input data). 


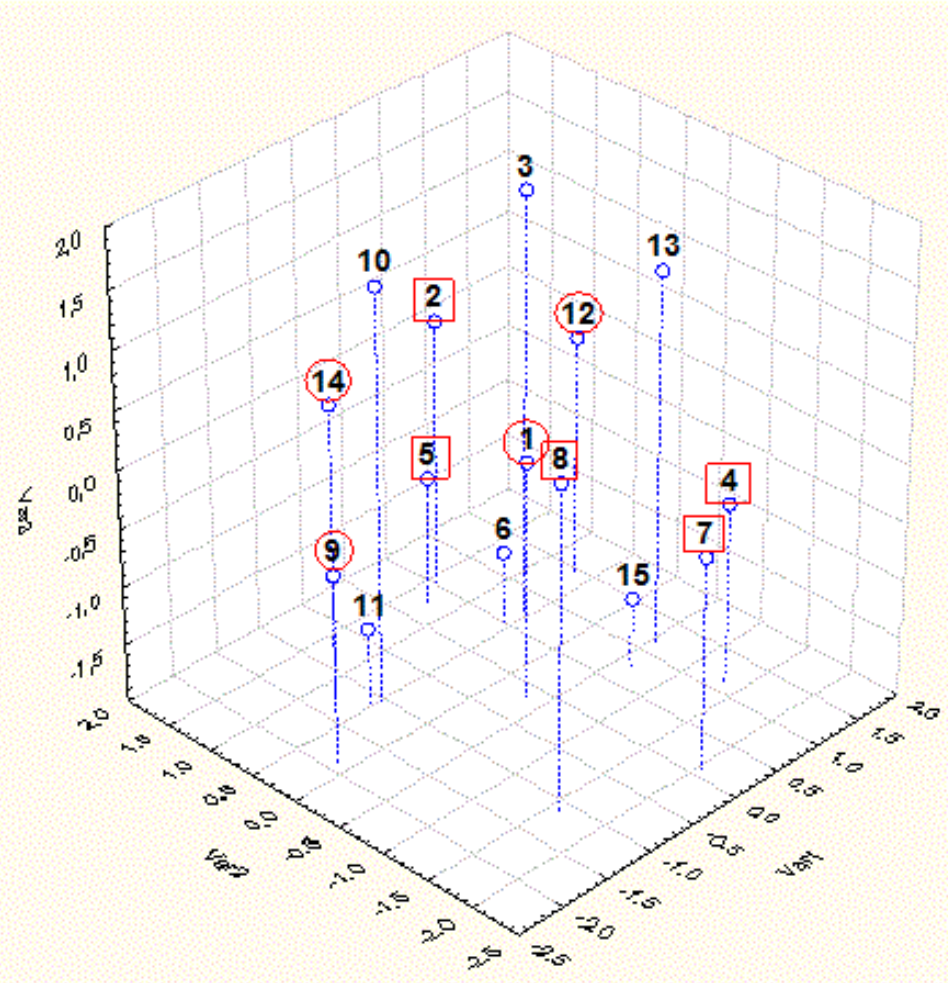

Fig. 2. Working pensioners: the space of parameters affecting well-being at work sphere

The results of multidimensional scaling allowed us to find out the major groups of problems prevailing in the minds of working pensioners. The first group (it includes categories with codes placed in a circle in Figure 2), was collectively denoted as "problematization of the meaning of life". The topic of overcoming perceived (category "loneliness") or expected (the category of "the idea that it is necessary to resign from work") meaninglessness of existence (codes 12 and 14 in Fig. 2, respectively) was presented in many messages of forum's visitors.

The phenomenon of "problematization of the meaning of life" indicates in many cases that the person is going through a critical situation in his life. For retired people such values as career, social status relegate to the background. Therefore, the work for many of them is turning into the action to overcome the "existential vacuum", and forums are turning into the tool to "express and formulate the problem, find the structure of meaning" (Wagner, 2010). U.L. Orlova drew attention to the importance of this parameter in a research conducted among different categories of elderly people (non-working pensioners who are in residential care), but for some reason she did not include it in the list of factors of the quality of life in old age (Orlova, 2015).

The second group of problems is indicated by us the term "external factors". It includes the categories that have, according to the results of multidimensional scaling, the highest or the lowest values on the second axis (see codes category placed in the square in Figure 2). Collectively they represent, as the analysis shows, the list of objective reasons, forcing pensioners to work or creating the 
http://dx.doi.org/10.15405/epsbs.2017.01.41

eISSN: 2357-1330 / Corresponding Author: Michail Kaz

Selection and peer-review under responsibility of the Organizing Committee of the conference

impediments to this. This list includes, for example, "financial necessity" (code 4), "low wages of working pensioner" (code 5) and other (Fig. 2).

The third group of problems is indicated by us as "factors of the physical and moral condition of pensioners: "hard work" (code 3), "health" (code 15) and others (see category codes that are not circled in Figure 2).

\section{Conclusion}

In the activity of social institutions, performing long-term care of elderly people (retirement homes, pensions, etc.), according many researchers, there are observed the features of duality. On the one hand, this social institutions help to maintain well-being of elderly people on the stage of life when possible help from relatives is not sufficient resources. On the other hand, they limit the personal freedom of the elderly, contribute to their social isolation (Orlova, 2015). Our research shows that working pensioners feel the dual sense too, that affects level of the perceived well-being and the quality of working life. However, if the main factors influencing the quality of life of elderly people, who live in residential institutions, providing social care services are:

- independence and autonomy;

- physical activity and the ability to care for themselves;

- social contacts with other people;

- the ability to participate in the practices of mutual aid and self-care (Aller, \& Coeling, 1995; Ball, \& Whittington, 2000; Hikoyeda, \& Wallace, 2001; Hjaltadottir, \& Gustafsdottir, 2007; Orlova, 2015),

then for working pensioners, as shown by our research, such parameters include:

- problematization of the meaning of life;

- external factors;

- factors of physical, spiritual and moral condition of pensioners.

A comparison of the content of two represented list shows that they coincide only insignificantly.

The world of working pensioners is an independent vital activity area, requiring specific research tools and methods of influence (Kaz, 2016). The analysis shows the urgent need for formulating and solving problems such as:

- the certification and improvement of the organization jobs that are suitable for pensioners work. The solution to this problem should be based on an understanding of the factors that most influence on the social well-being of working pensioners;

- the development the systems of monitoring of the social networking for pensioners in order to identify and resolve the problem situations disturbing them. Our veterans deserve enough attention to solve their problems with the help of authorities and local self-government.

\section{References}

Ajvazjan, S., \& Kamenskij, V. (1988). Preface to the Russian edition. M. Davison Multidimensional scaling. Methods of visual predstavleniya. M.: Finance and Statistics, 254. [in Russian]

Aller, L., \& Coeling, H. (1995). Quality of Life: Its Meaning to the Long-term Care Resident. Journal of Gerontological Nursing, 21, 20-25. 
Ball, M., \& Whittington, F. (2000). Quality of Life in Assisted Living Facilities: Viewpoints of Residents. Journal of Applied Gerontology, 19, 304-325.

Borgatti, S. (1997). Network analysis of 2-mode data. Social networks, 19(3), 243-269.

Charmaz, K. (2006). Constructing grounded theory: a practical guide through qualitative analysis. Thousand Oaks, CA: Sage.

Druzhinin, V. (2006). Experimental Psychology. SPb: Peter. [in Russian]

Hikoyeda, N., \& Wallace, S. (2001). Do Ethnic-specific Long Term Carefacilities Improve Resident Quality of Life? Findings from the Japanese American Community. Journal of Gerontological Social Work, 36, 83-106.

Hjaltadottir, I., \& Gustafsdottir, M. (2007). Quality of Life in Nursing Homes: Perception of Physically Frail Elderly Residents. Scandinavian Journal of Caring Sciences, 21, 48-55.

Kaz, E. (2016). Well-being and Management of Employee Incentives, The European Proceedings of Social \& Behavioural Sciences, VII, 295 -301.

Kaz, M. (2005). Labor motivation: the transformation of the structure of the theoretical methodological knowledge and cognitive approach., Voprosy jekonomiki, 12, 82-95. [in Russian]

Kaz, M. (2011). Sign and value in the models work: from the history of things to the history of ideas, Voprosy filosofii, 4, 41-52. [in Russian]

Kaz, M., \& Kuchkartaeva, A. (2016). Well-being and the Role of Working-Environment Factor: Research and Assessment, The European Proceedings of Social \& Behavioural Sciences, VII, 309315.

Kirk, J., \& Miller, M. (1986). Reliability and Validity in Qualitative Research. Newbury Park: Sage. Krippendorff, K. (2013). Content Analysis: An Introduction to Its Methodology. London: SAGE Publications.

Merton, H. (1977). A look at factors affecting the QWL. Monthli Labour Review, 100 (10), 64-86.

Neuman, L. (2011). Social research methods: qualitative and quantitative approaches. Boston: Pearson.

Orlova, W. (2015). Parameters of quality of life of elderly people living in residential care types. Sociological studies, 10, 103-110. [in Russian]

Vishnevsky, A. (2010). Saving the people or the depopulation of Russia. M.: High School of Economics. [in Russian]

Wagner, H. (2010). Gyvenimo Prasmès Ieskos Aspektai Socialinio Darbo Kontekste. Acta Pedagogica Vilnensia, 24, 20-31. 